\title{
Integrating Arsenic-Related Environmental Topics into the Education of the Next Generation of Citizens for Arsenic- Hit Communities: Awareness and Mobilization
}

\author{
Julian Tyson $^{1}$, Ray Kronquist ${ }^{2}$, Anowara Begum ${ }^{3}$, Shahena Begum ${ }^{4}$ \\ ${ }^{1}$ Department of Chemistry, University of Massachusetts Amherst, MA, USA \\ ${ }^{2}$ Chemists Without Borders, Sunnyvale, CA, USA \\ ${ }^{3}$ Department of Public Health Studies, Asian University for Women, Chittagong, Bangladesh \\ ${ }^{4}$ Department of Asian Studies, Asian University for Women, Chittagong, Bangladesh
}

\section{Email address:}

ray@kronquist.com (R. Kronquist), anowara.begum@auw.edu.bd (A. Begum), shahena.begum@auw.edu.bd (S. Begum), tyson@chem.umass.edu (J. Tyson)

\section{To cite this article:}

Julian Tyson, Ray Kronquist, Anowara Begum, Shahena Begum. Integrating Arsenic-Related Environmental Topics into the Education of the Next Generation of Citizens for Arsenic Hit Communities Awareness and Mobilization. International Journal of Environmental Monitoring and Analysis. Special Issue: Ground Water Arsenic Contamination and Action Plan for Mitigation. Vol. 3, No. 3-1, 2015, pp. 50-55. doi: $10.11648 /$ j.ijema.s.2015030301.16

\begin{abstract}
Several programs, organized by Chemists without Borders or the University of Massachusetts Amherst, in which secondary school or college students are introduced to the impact of arsenic contamination of the environment, and in particular of groundwater in Bangladesh, are described. A common feature is that students are recruited as members of a research group or investigative team and take ownership of the work by making relevant chemical measurements and participating in discussion of the implications of their findings. Leadership is provided in a hierarchical model in which, very often, more experienced students acting as near-peer mentors guide the activities of the newly recruited members of the groups. In some of the programs, the students work with teachers who have been trained by researchers on the university campus. Both in-school and out-of-school programs are described. A feature common to all is that chemical measurements are provided by low-cost field test kits based on the Gutzeit-Marsh reaction, the modification of which has provided a driving force for a considerable number of research projects for the college students. Many hundreds of students have been impacted and the programs, particularly that in Bangladesh, have considerable potential for empowering the students as agents of change in their communities as they not only take specific action as a result of their engagement but also educate other members of their families and communities about the potential hazards of consuming arsenic-contaminated water and rice and how these can be mitigated. Readers are invited to contribute to sustaining the program in Bangladesh and to initiate their own activities with students.
\end{abstract}

Keywords: Students, Education, Arsenic-Related Projects, Research Experiences, Community Engagement, Arsenic Mitigation

\section{Introduction}

'We're looking for Weapons of Mass Destruction (WMDs), I think they are in Bangladesh, and they are arsenic!' Unlike this statement made by a social worker, arsenic poisoning in drinking water in Bangladesh has already been identified as one of the world's greatest humanitarian disasters. Out of 150 million people in Bangladesh, 35-77 million people are at risk from arsenic contamination of water. It is estimated that between 1-5 million children are at risk of death by arsenicosis, or arsenic poisoning, by 2030 [1]. Chronic toxicity of arsenic affects the skin, nervous system, liver, cardiovascular system, and the respiratory tract. The emergence of the arsenic problem as a major public health issue can be traced back to the 1970s when the United Nations International Children's Emergency Fund (UNICEF) with other aid agencies began installing millions of tube wells in Bangladesh villages in an attempt to provide safe drinking water in Bangladesh. The program, which continued through the 1980s, was an early success. Instances of cholera, 
microbe-caused diarrhea, and other diseases dropped dramatically. But no one thought to analyze water for trace and ultra-trace impurities, and soon the good news turned bad. By the early 1990s, villagers began breaking out with skin disorders and experiencing fatigue symptoms of arsenicosis from imbibing the water.

Much has been written in the scientific literature related to gaining a deeper understanding of the biogeochemistry of arsenic, particularly those aspects that impact human health. In addition to the articles appearing in the peer-reviewed primary literature, there is a steady output of review articles in the secondary literature, and there are several excellent recent textbooks (the tertiary literature) covering both the global situation [1] as well as the slightly more specialized areas of groundwater [2] and rice contamination [3].

Although it is probably the case that interest in global arsenic-contamination issues in the scientific community, as evidenced by publications in scholarly journals, is at an alltime high, the outlook for the inhabitants of rural areas of Bangladesh, to select a subset of the world's population that are particularly at risk, would appear to be just as grim as it was when the scale of the problem was first brought to the world's attention some 30 years ago [1].

Clearly there are no simple, easily implemented solutions that would provide "arsenic-free" water in sufficient quantities to meet the requirements of communities in rural Bangladesh for drinking, cooking and irrigation of crops (particularly rice). On the other hand, many countries with arsenic-contaminated groundwater do not face the same catastrophic outcomes - probably because the citizens have expectations that in return for their tax contributions to central government, they will receive, among other services, some degree of protection from potentially harmful chemicals in their foods and drink. Should their particular circumstances put them outside the safeguards created by their government, they have the resources to make the necessary changes to their immediate environment and lifestyle.

However, even for the most developed nations in the world, public health is not necessarily the highest priority for governments facing other demands on their resources from areas that might be seen as equally, if not more, important, such as education, national security, and defense. The current debate in the United States over the long-term health implications of consuming rice (all of which is contaminated with carcinogenic arsenic compounds) provides an excellent example of the conflicting forces that shape public health policy in a capitalist democracy. From time to time, both scientists [4] and science writers [5] summarize the situation, usually concluding with a call for action. Items appear in the popular media related to some particular discovery, such as fruit juices sold in the United States contain measurable concentrations of arsenic, some of which may be in the form of the carcinogenic inorganic arsenic compounds, or that some wine may contain concentrations of arsenic higher than the maximum contaminant level of $10 \mu \mathrm{g} \mathrm{L}^{-1}$, set by the US Environmental Protection Agency and the World Health

\section{Organization.}

However, it is difficult for scientists to engage the public in any sustained way that would create a lasting awareness of any arsenic-contamination issues. In this article, we argue that an approach to public engagement that has the potential for long-term impact is to involve students (at all stages of the formal education processes) in projects related to arseniccontamination issues. These activities with students might be viewed as a subset of citizen science projects (see for example $[7,8]$ ) in which members of the public are recruited, primarily as data collectors, to on-going research projects. The focus of these activities is perhaps more on the concept of engaging the public in the generation of meaningful data to sustain the research program than it is on raising the awareness of the participants of a particular environmental problem that needs to be addressed. On the other hand, there are projects that are more focused on the education of students through the integration of environmental topics in the regular curriculum, such as some of the activities of World Water Watch [9] whose mission statement reads: "There is a great need for international educational programs at both the undergraduate and graduate levels. World Water Watch, together with partner organizations, is committed to "internationalizing-the-curriculum" at American universities, so that graduates will be better prepared to participate in and contribute to needed environmental protection and solutions." Chemists without Borders [10] "solves humanitarian problems by mobilizing the resources and expertise of the global chemistry community and its networks. The most common problems include poor water quality, maldistribution of medicines and vaccines, and lack of chemical education. Chemists Without Borders focuses on duplicating and providing proven solutions. Entrepreneurship is built into our programs as much as possible so that those we help can become more prosperous and help others. Recent and current projects include validation of a composite-ironmatrix arsenic-removal water filter, field verification of a low cost, low tech arsenic measurement device, provision of water filters for rural Bangladesh."

In this article, we describe both a number of activities in which students have been engaged as a result of several National Science Foundation initiatives at the University of Massachusetts Amherst, dating back to 2002, and a more recent project initiated by Chemists without Borders involving Bangladeshi students.

\section{Objectives}

The salient objectives are described as under;

1. Raise awareness of arsenic contamination of the environment, especially of ground water.

2. Have students inform their parents and other members of their communities about contaminated groundwater and other environmental problems

3. Educate students about low-cost mitigation strategies

4. Engage students in authentic science projects and research experiences 


\section{Chemists Without Borders Bangladesh Arsenic Education Project}

\subsection{Setting Up the Program}

Satinder Ahuja (Ahuja Consulting), Peter Ravenscroft (formerly with UNICEF) and Bego Gerber and Steve Chambreau, both of Chemists Without Borders (CWB), were instrumental in developing the conceptual plan for a project in Bangladesh to address this vital issue. The project's objective is to educate the population of Bangladesh about the hazards of arsenic in their drinking water via high school students. This includes visiting high schools to teach the importance of using only safe wells and safe water filters, and of operating these filters safely and sustainably.

To fulfill the goal of the project, Chemists Without Borders recruited five student graduates from the Asian University for Women (AUW) in Bangladesh as interns. Professor Amber Wise, a member of CWB, chemistry professor at Chicago State University and formerly a chemistry professor at the Asian University for Women (AUW), visited AUW in the summer of 2014 and arranged with the AUW Career Development Center to publicize the CWB internships. Ray Kronquist of CWB interviewed the applicants and hired five of them (four had received their BS degrees from AUW and one was in her senior year) to carry out the project starting Sept. 1, 2014.

\subsection{Running the Program}

The interns visited the schools and delivered a presentation, in the native language (Bangla), introducing Chemists Without Borders and the goal of the project. They then discussed with the students and teachers (mostly grades 8 to 10) the hazards of having excess arsenic in drinking water. They reviewed the background of the arsenic problem in Bangladesh, its symptoms, and possible mitigation strategies. It usually took around 45 to 60 minutes to explain all the information in the presentation. Then, interns demonstrated how to measure the arsenic in water using Hach EZ Arsenic Test Kits. Student representatives then practiced by repeating the measurements of arsenic in water using these kits. After that, the interns left the test kits, along with a sign-up sheet, for student volunteers who wanted to measure the arsenic in their own neighborhood water sources. The interns also left data sheets for recording the results, and an instruction manual in Bangla along with the interns' contact phone numbers. In each school, one teacher or student volunteer was in charge of keeping the data and test kits. After one week, the interns went back to the schools in order to monitor the work of the students' arsenic testing. Later the interns went back again to the schools and collected the test data and test kits from the responsible student or the teacher. To confirm the presence of arsenic in those schools, the interns also submitted water samples to Professor Dr. Reaz Akter Mullick (Assistant Professor, Department of Civil Engineering) at Chittagong University of Engineering and Technology (CUET), who conducted lab-based tests on the water samples.

\subsection{Results}

Using funds from a number of CWB donors, the interns have accomplished several positive outcomes. The activities ran for 16 weeks, starting on September 1, 2014, and ending on December 19, 2014. During the first 6 weeks of the internship, the interns were trained on the arsenic contamination history, testing and remediation methods, and the organization of the project. The funds were transferred by CWB from the U.S. to Bangladesh to pay the project expenses. The interns visited six high schools in different areas of Chittagong, Bangladesh: Chittagong Government Girl's High School, UCEP High School, Kumira Residential School and College, Sitakunda Model High School, Terial High School and ModdhomVaterkhil High School. The first high school visit was made on Oct. 16, 2014, and the last one was made on Nov. 13, 2014. The interns found $250 \mu \mathrm{g} \mathrm{L}^{-1}$ arsenic, which is 5 times more than the allowable concentration in Bangladesh, in two of the schools' tube wells, Sitakunda High School and Terial High School. In Sitakunda High School around 2500 people, and in Terial School around 1500 people are drinking water from these arsenic-contaminated tube wells. More information is available at [11].

\subsection{Next Steps}

Additionally, the interns consulted with experts from national and international organizations, such as Dr. Meera Smith (Founder and CEO of Project Well) and Dr. Matin (Professor of Geology, Dhaka University), to recommend the best option for ensuring safe drinking water in Sitakunda and Terial. They are planning to set up a ring well (which is also sometimes called a dug well) [12] in the two schools that have high arsenic, as suggested by the Department of Public Health Engineering (DPHE), a Bangladesh government organization that works in Sitakunda. The interns also built relationships with strategic and academic partners such as Dhaka Community Hospital, Dhaka University, Dhaka WASA (Water Supply and Sewage Authority), BRAC (formerly Bangladesh Rural Advancement Committee), UNICEF, WaterAid Bangladesh and CUET. They also used social media such as Facebook, LinkedIn and Indiegogo to raise awareness among youths and others.

This project is developing a protocol for awareness about arsenic hazards in drinking water in Bangladesh and it can be easily scaled up from local communities to a national level through high school students. The students are able to convey the message about arsenic hazards in drinking water to their family members, neighbors, community members and their relatives as well. Also, by providing safe drinking water from safe sources, this project is ensuring one basic right of the people: access to clean water. Currently Chemists Without Borders is working with Rotary Club Chittagong to provide safe drinking water to around 2500 people in Sitakunda, which is one of the arsenic-prone areas in Bangladesh. To 
ensure adequate funding, CWB is looking forward to collaborating with other organizations.

Additionally, to raise funds, a group of enthusiastic U.S. high school and college student volunteers, who have been meeting weekly on Skype for the past several months, is spreading the word in different schools in the U.S. about the CWB Bangladesh Arsenic Education Program. CWB greatly appreciates and invites any involvement of individuals or organizations to continue enlightening the youth of Bangladesh about arsenic. For further inquiries about the project in Bangladesh or about the U.S. support group, please contact Ray Kronquist (ray@kronquist.com), Anowara Begum (anowara.begum@auw.edu.bd) and Shahena Begum (shahena.begum@auw.edu.bd).

\section{The University of Massachusetts Amherst Programs}

\subsection{Graduate Students in K-12 Education}

Many of the activities in which students and their teachers have been engaged have been organized by the universities STEM Education Institute, at whose website [13] further details may be found. In 2002, the University received a grant from the NSF's Graduate Student in K-12 Education (GK-12) program, and for four years organized a program in which graduate students spent several hours a week in middle-school classrooms working with the teachers to implement inquiry-based learning activities around the research interests and scientific expertise of a number of faculty members. One of the topics was arsenic-in-the environment, directed by Julian Tyson. At the time, not only was arsenic contamination of drinking water a prominent topic, but also there was considerable debate about the possibilities for arsenic ingestion as a result of contact with wooden structures pressure-treated with chromated copper arsenate (CCA), and of the leaching of arsenic into the soil. As one of the goals of the program was to for students to understand the importance of chemical analysis, it was necessary to find a way to integrate chemical measurement into the classroom activities and not take samples back to the university campus and present the students with results. We chose the Hach 5-reagent kit to start with and then switched to the EZ kit when it became available, as it is less expensive and quicker. We realized that for almost all of the materials we were examining, it was not necessary to deal with a possible interference from sulfide. None-the-less, it was still not possible for students to prepare materials and run a test in one class period, and so the 24-hour version of the test was born, in which the strip was read in class the following day, 24 hours after the reaction was initiated rather than the 20minutes recommended by the manufacturer.

Meeting the in-class needs for chemical measurement stimulated an interest in field test kits, particularly those base on the Gutzeit modification of the Marsh test. The timely arrival of an NSF research grant in 2003 allowed some of these interests to be followed while strengthening active involvement with one of the teachers and her students through the "broader impacts" components of the grant. This program was selected, following a national competition, as an exemplary broader impact component and was showcased at an American Chemical Society National Conference in Washing DC in 2005 [14],

\subsection{Undergraduate Independent Study}

In fall 2004, an arsenic-related research experience modeled on the success with the middle school students in the GK-12 project was created for undergraduate students at UMass Amherst taking the first- or second-semester of the general chemistry sequence. This program has now run for 19 semesters and over 500 students have participated. The basic format is that students work in small groups, sometimes with a more experienced undergraduate, on a project related to Professor Tyson's interests in the environmental and analytical chemistry of arsenic compounds. There are several goals for this activity: getting the undergraduate student participants interested in research by creating an "authentic" research experience, raising awareness of the impacts of the transport and transformations of arsenic compounds in the environment, and inculcating an understanding of the critical importance of reliable chemical analysis in underpinning these kinds of studies. The plight of rural communities in Bangladesh is always featured in the background to many of these projects.

Participants in the arsenic project write (a) a background paper that includes a description of one measurement technique, and some suggestions for the initial experiment (not exactly a research proposal, but the analogue of one), and (b) a final report in the form of a journal article. For most of the semester, outside of the lab each group works period to its own schedule, set by the members of that group. However, all the groups come together on three occasions, in addition to the very first meeting, at which each group makes a PowerPoint-assisted presentation of their progress. Each member of the group contributes to the oral presentation. Everyone in the program is therefore exposed to the topics that the other groups are working on, which always include a number related to the low-cost, small scale remediation of contaminated ground water. Other projects are concerned with improvements in the Hach test kit, or the development of methods of analysis for materials, such as soils, for which the kit is not originally designed. Recently several projects have been focused on the extraction and determination of arsenic compounds in rice.

This introduction to the relevant issues has been an effective way of recruiting undergraduate students into the Tyson research group and since the fall of 2004, about 60 students have worked on independent studies, many of which lasted for multiple semesters. In addition, NSF supplements to research grants and an Alliance for Graduate Education and the Professoriate, a major NSF initiative aimed at increasing participation in STEM graduate programs by under represented minorities (known as the NE Alliance [15]) funded about 16 participants in REUs (research experiences 
for undergraduates) in the Tyson group, almost all of whom worked on arsenic-related topics.

\subsection{Research Academies for Young Scientists}

In the fall of 2006, the first cohort of teachers started work on after-school programs in an NSF-funded program called Research Academies for Young Scientists, known on the UMass Amherst campus as STEMRAYS [16]. In this program teachers ran after-school science clubs on environmental. Arsenic topics formed the basis for activities by five teachers, each of whom led a club of about 10 students (grades $4-6$ ). The following year, two teachers were trained to be club leaders. There was an education research component to the project and the results formed the basis of a publication in the science education literature [17].

\subsection{Innovative Technology Experiences for Students and Teachers}

In the fall of 2010 , work started on creating materials for the teacher participants in an NSF-funded Innovative Technology Experiences for Students and Teachers (ITEST) program. The UMass Amherst program was known as STEM DIGITAL (digital images in geoscience investigations: teaching analysis with light) and once again featured several environmentally related themes for which chemical measurement was needed. This time all the measurements were of the interaction of ultraviolet, visible or infrared light with relevant materials captured in digital images that were subsequently analyzed by suitable software. For three summers, 30 teacher participants learned about the problems of arsenic contamination of groundwater and of rice and of the role of spectrochemical analysis (as exemplified, at least for the arsenic-related projects, by the Gutzeit-Marsh reaction augmented by digital image analysis) in supporting such investigations. This theme, of improvement through digital image analysis, formed the basis of part of a doctoral dissertation in, and subsequent publication by, the Tyson group [18]. The teacher participants took materials back with them to further develop curricular materials for their students.

\subsection{Junior-Year Writing in Chemistry}

The University of Massachusetts Amherst has a writing requirement consisting of two, three-credit, writing-intensive courses: Introduction to College Writing, taken in the first year, taught by instructors in the University Writing Program, and junior-year writing in the discipline taught by a discipline-specific instructor working in collaboration with a writing specialist. From 1996, members of the UMass Chemistry program's junior-year writing class (essentially all chemistry majors) taught by Professor Tyson (and Professor Holly Davis, a writing specialist at Smith College) were given an exercise in which they were asked to write an article for a non-science readership based on the contents of one original article in the primary peer-reviewed literature. Of the 16 times that this version of the course has been offered over the past 20 years, on 12 occasions the class was asked to explain the technical scientific content of "Arsenic in groundwater in 6 districts of west-Bengal, India - the biggest arsenic calamity in the world: 1 . arsenic species in drinking-water and urine of the affected people" in language accessible to a non-scientific readership. [19] In recent years, students were asked to write about the contents of either "Anthropogenic influences on groundwater arsenic concentrations in Bangladesh" [20] or "Arsenic levels in rice grain and assessment of daily dietary intake of arsenic from rice in arsenic contaminated regions of Bangladesh — implications to groundwater irrigation" [21]. Although the classes contained some students who had been involved in the general chemistry arsenic-related research projects that started in 2004 , it is estimated that a further 300 chemistry students have learned about the ground-water contamination in SE Asia, and of the importance of chemical analysis in supporting research directed towards an understanding the associated geochemistry and the impact on the local populations.

Instructional materials developed for the class formed the basis for a textbook in the Pearson Longman "Short guide to writing" series [22]. Arsenic-in-the-environment topics are featured, though not to the exclusion of other topics, in the book when examples of particular types of writing are needed. As nearly 7,000 copies of the book have been sold (by December $31^{\text {st }} 2014$ ), it might be argued that the numbers of students aware of these topics is more than just the numbers of students taking the classes on the UMass Amherst campus.

\section{Conclusions}

The Chemists Without Borders Bangladesh team members strongly believe that, while it may not be apparent what such interactions between educated youth and their communities will yield in the short term, each interaction can have the 'potential of lighting a match to a candle', of igniting many young minds in ways that can bring a positive change in the society.

At UMass Amherst, in the 13 years since students have been involved in environmental and analytical chemistry investigations, it is estimated that over 500 hundred middle and high school students and over 600 undergraduates have been exposed to, and even immersed in, topics relating to the groundwater contamination in Bangladesh. Over the same period of time, some 17 doctoral students successfully completed studies in the Tyson group, almost all of whom were involved in the mentoring of undergraduate students working on arsenic-related projects, and for several the contents of their dissertations also involved arsenic-related topics. Seven of these former students are now working as chemical educators in high schools or colleges, mostly in the USA (one is in SE Asia and one in Africa). As a member of the first cohort of Public Engagement Fellows (2015) at UMass Amherst, Professor Tyson is creating a website (still under construction) that will provide information on many of the topics relevant to understanding the implications of the 
presence of arsenic compounds in our food and drink. He is also currently teaching a physical sciences general education course in the CHEM 101 series, entitled "How much arsenic do we eat?" in which he explains to non-science majors the science behind answering this question and the closely related questions of "Are we at risk?" "How do we know what the concentrations of the toxic compounds are?" and "How reliable are the measurements?" The course is offered on campus to matriculated students and to non-degree students through the UMass Continuing and Professional Education Organization. He is willing to share such resources as he can with educators wishing to engage their own students in arsenic-related projects.

\section{Acknowlegements}

The various projects on the UMass Amherst Campus have been supported by funding from the following NSF grants: DGE-0139272, CHE-0316181, DRL-103115. Professor Tyson was awarded a National Science Foundation Discovery Corps Senior Fellowship (CHE-0725257) in 2007, which allowed him to travel to several countries in SE Asia, including Bangladesh. Funding from the Camille and Henry Dreyfus Foundation and the US Geological Survey for the development of undergraduate research projects is gratefully acknowledged. The American Chemical Society is thanked for the sponsorship of a public lecture-demonstration "How much arsenic do we eat?" in December 2011.

\section{References}

[1] S. V. Flanagan, R. B. Johnston, and Y. Zheng, "Arsenic in tube well water in Bangladesh: health and economic impacts and implications for arsenic mitigation," Bulletin of the World Health Organization, vol 90, pp. 839-846, September 2012.

[2] R. Ravenscroft, H. Banner and K. Richards, Arsenic Pollution, A Global Synthesis, Wiley-Blackwell, Chichester, 2009, pp. 588 .

[3] Arsenic Contamination of Groundwater: Mechanism, Analysis and Remediation, Ed. S. Ahuja, Wiley, Hoboken, 2008, pp. 387.

[4] A. A. Meharg and F-J. Zhao, Arsenic \& Rice, Springer, Dordrecht, 2012, pp.171.

[5] A A. Meharg and A. Raab, "Getting to the bottom of arsenic standards and guidelines", Environ. Sci. Technol., vol 44, pp 4395-4399, 2010

[6] C. W. Schmidt, "In search of 'just right:' the challenge of regulating arsenic in rice," Env. Health Perspectives, vol 123, pp. A17-A19, January 2015.
[7] Citizen Scientists, http://www.citizenscientists.com (accessed April 2015)

[8] The Citizen Science Alliance, http://www.citizensciencealliance.org/index.html (accessed April 2015).

[9] World Water Watch, http://www.worldwaterwatch.org/ (accessed April 2015).

[10] Chemists without Borders, http://www.chemistswithoutborders.org/ (accessed April 2015)

[11] Chemists without Borders Bangladesh Arsenic Education, https://www.indiegogo.com/projects/chemists-withoutborders-bangladesh-arsenic-educ-n/ (accessed April 2015).

[12] Bangladesh Department of Public Health Engineering, http://www.dphe.gov.bd/index.php?option=com_content\&vie $\mathrm{w}=$ article \&id=96\&Itemid $=104$ (accessed April 2015)

[13] STEM Education Institute, University of Massachusetts, Amherst http://umassk12.net/stem/ (accessed April 2015).

[14] National Science Foundation, http://www.nsf.gov/pubs/2005/nsf0540/nsf0540.jsp. (accessed April 2015).

[15] North East Alliance for Graduate Education and the Professoriate, http://www.neagep.org/ (accessed April 2015).

[16] Research Academies for Young Scientists, http://umassk12.net/rays/ (accessed April 2015).

[17] A. Feldman and K. Pirog, "Authentic Science Research in Elementary School After-School Science Clubs," J. Sci. Educ. Technol., vol 20, pp. 494-507, May 2011.

[18] J. Kearns and J. Tyson, "Improving the accuracy and precision of an arsenic field test kit: increased reaction time and digital image analysis," Anal. Methods, vol 4, pp 1693 - 1698, 2012.

[19] A. Chatterjee, D. Das, B. K. Mandal, T. R. Chowdhury, G. Samanta, and D. Chakraborti, "Arsenic in ground-water in 6 districts of west-Bengal, India - the biggest arsenic calamity in the world: 1. arsenic species in drinking-water and urine of the affected people," Analyst, vol 120, pp 643-650, March 1995.

[20] R. B. Neumann, K. N. Ashfaque, A. B. M. Badruzzaman, M. Ashraf Ali, J. K. Shoemaker, and C. F. Harvey, "Anthropogenic influences on groundwater arsenic concentrations in Bangladesh," Nature Geoscience, vol 3, pp 46-52, January 2010.

[21] M. M. Rahman, G. Owens, and R. Naidu, "Arsenic levels in rice grain and assessment of daily dietary intake of arsenic from rice in arsenic contaminated regions of Bangladeshimplications to groundwater irrigation," Environmental Geochemistry and Health Vol. 31, pp. 179-187, 2009.

[22] H. B. Davis, J. F. Tyson, and J. A. Pechenik, "A short guide to writing about chemistry,” Longman, New York, 2010. 